\title{
Marketing e o comportamento do consumidor on-line: metodologia e a evolução nas produções científicas de 2014 a 2018.
}

\section{Marketing and on-line consumer behavior:methodology and developments in scientific productions from 2014 to 2018.}

\section{Larissa Maruitia ${ }^{\mathrm{a}}$ Renata Forato Brigagãob, Thel Augusto Monteiro ${ }^{\mathrm{c}}$}

${ }^{a}$ Mestre em Educação. Universidade Metodista de Piracicaba UNIMEP. canalexterior@yahoo.com.br

${ }^{\mathrm{b}}$ Mestre em Administração. Universidade Metodista de Piracicaba UNIMEP. reforatob@gmail.com

${ }^{\text {c }}$ Doutor em Administração Universidade Metodista de Piracicaba UNIMEP. thel.augusto@me.com

\section{Resumo}

O presente estudo tem como alvo analisar as produções cientificas no que tange suas metodologias. O volume de produção e a qualidade científica podem ter grandes aliados quando se elabora uma descrição sobre os tipos de métodos mais aplicados para o estudo e outras possíveis informações que podem ser extraídas e apresentadas. Trata-se de uma contribuição que facilita a visualização e até os próximos métodos a serem aplicados nas próximas pesquisas. O objetivo deste trabalho é analisar a metodologia das publicações do período de 2014 a 2018, relacionadas ao tema e extraídas da base de dados Scopus e Capes. Este estudo descritivo apresentou a metodologia quali- quantitativa e analisou 10 artigos extraídos da base de dados Scopus e Capes por meio dos descritores "concept" and "consumerbehavior" e "marketing" and "on-line". Foi possível apresentar que no período analisado as publicações tiveram oscilações. As produções científicas analisadas tiveram $70 \%$ de metodologias quali-quantitativa, com a presença da pesquisa exploratória em $70 \%$ dos estudos. O Survey detém $40 \%$ dos tipos de método positivista e a forma de realizar a coleta de dados o questionário sobressaiu-se às demais, com $50 \%$ de utilização.

Palavras-chave: Comportamento do Consumidor On-line; Marketing; Metodologia; Produção Científica.

\begin{abstract}
The present study aims to analyze the scientific productions regarding their methodologies. Production volume and scientific quality can have great allies when developing a description of the types of methods most commonly applied for the study and other possible information that can be extracted and presented. It is a contribution that facilitates the visualization and even the next methods to be applied in the next research. The objective of this paper is to analyze the methodology of publications from 2014 to 2018 , related to the theme and extracted from the Scopus and Capes database. This descriptive study presented the qualitative and quantitative methodology and analyzed 10 articles extracted from the Scopus and Capes database through the descriptors "concept" and "consumer behavior" and "marketing" and "online". analyzed publications had oscillations. The scientific productions analyzed had $70 \%$ of qualitative and quantitative methodologies, with the presence of exploratory research in $70 \%$ of the studies. The Survey has $40 \%$ of the positivist method types and how to perform data collection. the questionnaire stood out from the others, with $50 \%$ of use.
\end{abstract}

Keywords: Consumer Behavior Online; Marketing; Methodology; Scientific production 


\section{Introdução}

A relação entre pesquisa e conhecimento já era pensada por Aristóteles que defendia que novas ideias surgem por meio da contraposição e contradição de ideias anteriores, ou seja, deve-se conhecer o que todos falam sobre um assunto para a evolução no conhecimento (Chueke \& Amatucci, 2015).

O conhecimento e a pesquisa fazem parte de uma complexidade que no lado positivo está vulnerável a novas descobertas por meio dos estudos. O marketing carece de muitas descobertas para diminuir o vácuo que existe para preencher algumas respostas, uma delas a necessidade de construção teórica da disciplina (Scussel, 2017).

Um avanço é percebido nas temáticas Marketing Social, Teoria de marketing e Sociedade de Consumo. Isso pode significar maior interesse dos pesquisadores pela reflexividade dos estudos críticos, o que poderá reverter em novas formas de construção de modelos e ações de marketing (Maranhão \& Paula, 2007).

Somado a esse resultado de carência de estudos críticos a mensuração faz-se aliada para ter um panorama sobre a real situação das produções e para qual caminho elas seguem. Para mensurar esse avanço, torna-se imprescindível no âmbito dos métodos de pesquisa estudar os artigos e conhecer a produção e a qualidade dos mesmos.

Desta forma, entende-se que a metodologia é essencial para a obtenção dos objetivos de pesquisa, e o rigor com que é utilizado confere a mesma credibilidade nos seus resultados e assim sendo contribui de maneira eficaz para aprimorar e aprofundar o conhecimento sobre os temas a serem investigados.

Mazzon e Hernandez (2013), corroboram em seus achados que o assunto "Comportamento do consumidor" sobressai aos outros. Temas requisitados e que se relacionam com a inserção da tecnologia podem ser pontos de alta atratividade para novas pesquisas como "Marketing e o comportamento do consumidor online".

Estes mesmos autores explanam que os artigos inscritos em Anais de Encontros e Congressos tem superioridade à participação de artigos em periódicos. Importante evidenciar que os temas atrativos e as metodologias aplicadas de forma correta não têm espaço garantido em veículos de comunicação científica.

$\mathrm{O}$ volume de produção científica e sua qualidade podem ter grandes aliados para complementar as informações de futuros estudos, um deles é a descrição dos métodos mais aplicados para o estudo, e a outra, são os dados que podem ser extraídos e apresentados.

O presente estudo contribui com o meio científico por mensurar o que já foi produzido num certo período, e assim torna-se relevante por viabilizar o planejamento de métodos a serem aplicados nas próximas pesquisas.

Mazzon e Hernandez (2013) observam que análises periódicas de produções científicas são úteis para os pesquisadores, pois proporcionam um mapa mensurador da real situação das produções e seus temas.

O objetivo principal deste trabalho é analisar a metodologia das publicações do período de 2014 a 2018, que estão relacionadas ao tema e extraídas da base de dados Scopus e Capes. Esse estudo também permeou para a análise do volume de publicações no período, as palavras referenciadas nos resumos dos artigos obtidos, e a apresentação das mesmas.

Este trabalho descritivo, de cunho qualitativo e quantitativo buscou analisar 10 artigos obtidos da base de dados Scopus e Capes, resultantes de uma filtragem por meio de seleções e leituras. Posteriormente classificou e identificou as metodologias de cada artigo e posteriormente captou dados por meio do software Iramuteq em relação as palavras que compunham o resumo.

O trabalho está segmentado em cinco partes: Introdução, Fundamentação Teórica com uma breve 
explanação sobre a produção científica e os métodos existentes de acordo com os conceitos dos autores; Metodologia; Resultados que traz a apresentação dos números obtidos juntamente com as análises; e Considerações finais.

\section{A produção científica brasileira}

As produções científicas contribuem para a evolução das pesquisas, assim aprofundar a investigação no âmbito das produções é fato interessante para quantificar e entender as pesquisas de um determinado tema. Portanto, quando o assunto é produção acadêmica, a administração é a área que tem o maior domínio pelas citações ao marketing (Barcelos \& Rossi, 2015).

Nas observações de Mazzon e Hernandez (2013) os trabalhos que apresentam análise periódica da produção científica são muito bem quistos, por proporcionarem cenários de parâmetros comparativos.

É notório a dificuldade de se conseguir um espaço para divulgar o trabalho acadêmico. Essa dificuldade torna-se mais comum ainda quando um veículo de publicação científica é o Journalof Marketing, considerado de alto nível, como enfatiza Kumar (2016). E posterior a essa árdua conquista, também tem as citações desses artigos nos próximos trabalhos por outros autores.

A média de citações por artigos e a média de citações de periódicos nacionais apresentaram aumento, e o tema comportamento do consumidor continua sendo o assunto que mais atrai o desenvolvimento de artigos (Mazzon \& Hernandez, 2013).

Segundo Barcelos e Rossi (2015) os cuidados com a metodologia, modelagem e estatísticas são muito abordados nos artigos de marketing. Ao adentrar no assunto sobre a metodologia, a qualidade e o rigor da mesma oportunizam ressaltar que são características importantes para a confiabilidade nos resultados desses trabalhos.

Importante destacar que nos trabalhos realizados sobre as tipologias do método de pesquisa os resultados mostram que em outras áreas, mesmo sendo elas afins, os artigos também não apresentam adequadamente a metodologia empregada para a realização da pesquisa. Essa vulnerabilidade parece estar presente nas pesquisas independentes de suas áreas mesmo em um Congresso renomado como da Universidade de São Paulo apenas $47 \%$ dos artigos especificaram os procedimentos em uma ou outra categoria (Ribeiro et al., 2013).

Os autores salientam que a principal conclusão é de pouco rigor metodológico na condução das pesquisas e/ou elaboração dos artigos. De fato, nas discussões dos autores fica evidente a fraqueza na cientificidade da pesquisa, por conseguinte, na validade e confiabilidade dos achados das pesquisas. Seus resultados também dependem entre outros aspectos da metodologia de pesquisa, ou seja, há vulnerabilidade na metodologia.

\subsection{A pesquisa com base nos objetivos}

As pesquisas segundo Gil (2002) são procedimentos racionais que seguem um padrão para serem executadas, e são realizadas para trazer respostas de ordem intelectual ou de ordem prática.

As pesquisas antes mesmo de serem realizadas já possuem um propósito, que se refere ao oque se pretende obter com esse estudo. Portanto com base nesses propósitos é que alguns autores fazem a classificação dessas pesquisas.

Para Gil (2002), classificar a pesquisa com base nos objetivos torna-se possível realizar em três grandes grupos: exploratórias, descritivas e explicativas. A pesquisa descritiva, utilizada neste estudo tem como alvo a descrição das características de determinada população ou fenômeno, ou então o estabelecimento de relações 
entre variáveis. Tendo como característica principal a padronização das técnicas de coleta de dados.

Nas pesquisas descritivas, o mesmo autor menciona que os fatos são observados, registrados, analisados, classificados e interpretados, sem que o pesquisador interfira sobre eles, ou seja, os fenômenos do mundo físico e humano são estudados, mas não são manipulados pelo pesquisador.

A pesquisa exploratória tem como característica trabalhar com um assunto de forma a esclarecêlo melhor, pois o mesmo já é pouco explorado, isso pode acarretar na modificação dos conceitos e ideias do mesmo, tendo em vista a formulação de problemas mais precisos ou indagações surgidas para estudos posteriores (Gil, 2008).

Segundo o mesmo autor, na pesquisa explicativa o objetivo é encontrar a razão, o porquê de estar acontecendo um fato. A grande contribuição do conhecimento científico está nas respostas desses estudos explicativos.

Ao realizar uma pesquisa, nota-se nas escritas de Gil, que deverá ser escolhido se a mesma terá como atribuição: trazer uma explicação, apenas relatar por meio da escrita os fatos que ocorrem, ou aprimorar um assunto novo, desconhecido.

\subsection{A pesquisa quanto a metodologia}

A Pesquisa Científica visa a conhecer cientificamente um ou mais aspectos de determinado assunto. Para tanto, deve ser sistemática, metódica e crítica. O produto da pesquisa científica deve contribuir para o avanço do conhecimento humano (Pradanov \& Freitas, 2013).

A pesquisa científica para ser desenvolvida e obter resultados precisos, necessita seguir alguns critérios que levam para um tipo de identificação. Essa identificação para autores como Collis e Hussey (2005) são chamadas de método positivista e método fenomenológico.

Segundo os mesmos autores o método positivista apresenta quatro tipos de estudos sendo eles: corte transversal, experimental, longitudinal e surveys. Já o método fenomenológico se subdivide em pesquisa ação, estudo de caso, etnografia, perspectiva feminista, teoria fundamentada, hermenêutica e inquirição participante.

No trabalho de Gil e Aranha (2017) foi discutido que as disciplinas são heterogêneas por natureza, portanto mesmo que elas apresentem sua teoria, seu método e forma de fazer pesquisa não estão isentas de serem alvo de debates que proporcionam os estudos do mesmo objeto chegando a formas e resultados diferentes.

Nesse diapasão, essa autora acha interessante mencionar que Creswell (2007) não se apodera dos mesmos termos utilizados por Collis e Hussey ao mencionar os métodos de pesquisa positivista e fenomenológica. O primeiro autor as nomina como quantitativa e qualitativa respectivamente. Embora os autores mencionados utilizam termos distintos para nomear os tipos de pesquisas, essa autora opta por utilizar ambos para a identificação da metodologia.

Na realização da pesquisa, chega um momento onde o pesquisador deverá escolher uma técnica para ter acesso aos dados, para isso deverão realizar a coleta dos mesmos. A coleta de dados pode acontecer por meio da técnica de incidente crítico, diários, grupos de foco, entrevistas, observação, análise de protocolo, e questionários (Collis \& Hussey, 2005).

Nas explanações dos autores mencionados fica evidente para esta autora que as metodologias existem, e são várias, e a escolha delas acaba por determinar o rumo de um estudo com possibilidade de até mesmo alterar os panoramas diversos de uma sociedade. 


\section{Metodologia}

Este trabalho tem como objetivo verificar quais metodologias são utilizadas nos estudos científicos que envolvem o marketing e o comportamento do consumidor. Neste âmbito realizou-se uma pesquisa descritiva de cunho qualitativo e quantitativo. Para a localização e identificação das metodologias foi necessário realizar uma análise de conteúdo nos artigos obtidos por meio da bibliometria.

Silva e Fossá (2015) explanam que a análise de conteúdo abarca uma organização sistemática do material que será investigado, esse procedimento oportuniza e facilita novas operações que compreendem as fases de leitura flutuante, a escolha de documentos, a formulação de hipóteses e objetivos e a elaboração de indicadores.

A análise de conteúdo envolve a leitura do material de forma a explorar o máximo, destarte não permite deixar nada de fora, e a organização desse material se dá por: pré-análise, exploração do material, e tratamento dos resultados (Bardin, 1977).

Outro método também utilizado foi o qualitativo por meio da bibliografia. O objetivo da bibliografia segundo Lakatos \& Marconi (2001) é colocar o pesquisador diante de tudo que foi escrito, dito ou filmado sobre determinado assunto. É um tipo de pesquisa que não têm o compromisso de explicar os fenômenos que descreve, embora sirva de base para tal explicação (Vergara, 1998).

Verificação da metodologia por meio da pesquisa bibliográfica pretende demonstrar quais métodos científicos são mais utilizados nas pesquisas em relação ao tema deste estudo e a partir desta análise proporcionar uma maior contribuição ao conhecimento.

O período selecionado para a busca dos artigos foi de 2014 a 2018, e o download dos documentos foi realizado no mês de outubro de 2019. Os descritores foram: "concept" e "consumerbehavior"; e "marketing" e "on-line". Ao realizar a busca na base de dados Capes - Coordenação de Aperfeiçoamento de Pessoal de Nível Superior, 70 artigos foram encontrados. Após essa etapa foi selecionado o termo "Business" por meio da filtragem que o próprio portal disponibiliza, e o número de artigos caiu para 33. Ao ler os resumos duas vezes, mais a introdução e as considerações dos 33 artigos, esta autora classificou que somente 04 tem aderência com o tema.

A segunda base de dados escolhida para a busca de artigos foi a SCOPUS - Scientific Eletronic Library On-line. Nesta base de dados foi selecionado os itens "Business" e "Psycology" para realizar a filtragem, que trouxe como resultado 16 artigos. O descritor Psycology foi selecionado pelo fato do assunto "comportamento do consumidor" estar presente na disciplina de psicologia. Na dupla leitura dos resumos, a introdução e as considerações, foi observado por esta autora que somente 06 tem aderência com o tema. Portanto, o total de artigos para a realização desta pesquisa extraídos das duas bases de dados foram 10, e que para as análises da metodologia foram lidos na íntegra mais de duas vezes.

Quando se refere ao abstract, Motta e Iizuka (2018) explanam que é a parte inserida no início do artigo e que tem como função apresentar um panorama resumido do qual o artigo se propõe pesquisar.

O abstract é moldado pela heterogeneidade construtivista, manipulado por seus autores com o intuito de cumprir seus propósitos, assim sua estrutura é flexibilizada conforme o modo de transmitir o conteúdo da pesquisa (Gil \& Aranha, 2017).

$\mathrm{Na}$ posse dos 10 artigos seguiu-se o procedimento para realizar as classificações dos mesmos em relação à metodologia aplicada, conforme abaixo:

- Obtenção do nome do periódico e o ano em que o artigo foi publicado; 
- Leitura do artigo na íntegra para a identificação: do método aplicado; do objetivo da pesquisa; da forma de coletar os dados;

- Elaboração de uma tabela no programa wordpara preencher e quantificar as identificações citadas acima;

- Elaboração de uma tabela com o nome do país do autor principal do trabalho, e o nome do país alvo da pesquisa;

- Utilização do software Iramuteq com os 10 artigos para obter medições de palavras dos resumos;

A pesquisa qualitativa permite vasta gama de resultados, que um meio de facilitar e agilizar o manuseio dos mesmos são com a utilização de softwares CAQDAS - Computer-AidedQualitative Data Analysis Software. O manuseio desses softwares proporciona informações precisas com capacidade de conectarem uma com as outras e gerar relatórios de diversas espécies, ou seja, gerenciam os processamentos de dados, e a análise continua sendo da responsabilidade do pesquisador (Gil, 2008).

Dentre os diversos softwares disponibilizados gratuitamente, o Iramuteq foi escolhido para viabilizar as análises de dados textuais, facilitar a identificação e a possível conexão das palavras contidas nos resumos dos artigos analisados. Um dos softwares que compõem o CAQDAS, é o Iramuteq. Este software organiza o vocabulário de forma a facilitar a compreensão das palavras, gerencia os arquivos, torna a apresentação lexicográficas mais atrativa, agiliza a codificação e a obtenção de respostas (Schlosser, Frasson \& Cantorani, 2019).

\section{Análise e discussão dos resultados}

\subsection{Análise da produção no período}

A pesquisa realizada com base no tema oportunizou fazer um levantamento dos artigos publicados por ano. Assim foi possível verificar e quantificar que no ano de 2013 apenas 01 artigo foi publicado, e outro no ano de 2014. Já em 2015 foram 03 artigos publicados. Nos dois anos posteriores aconteceu somente uma publicação por ano. Em 2018 foi para 3 publicações, conforme a Figura 1.

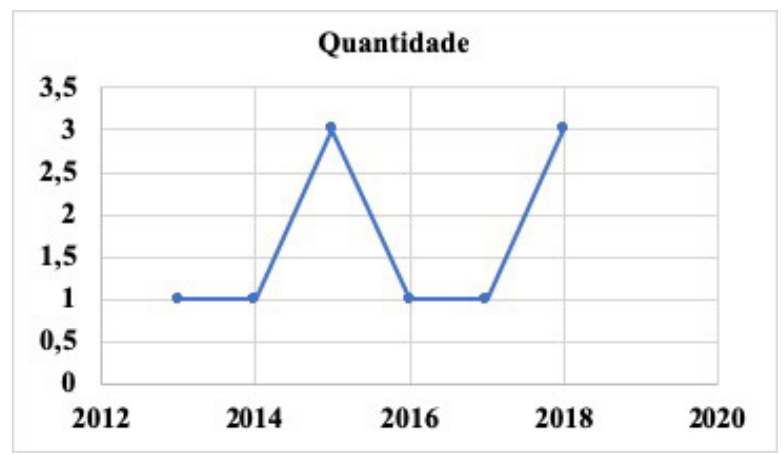

Fig. 1. Quantidade de artigos publicados por ano

O trabalho de Moreira, mensurou as publicações no período de 2014 a 2018 sobre outro tema, porém na mesma área, e as oscilações também estiveram presentes. Portanto é compreensível ocorrer oscilações na quantidade de publicações de artigos de um determinado tema no período.

\subsection{Análise da metodologia}

Quanto aos métodos, pode-se constatar que dos 10 artigos lidos, 03 deles apresentaram método 
qualitativo, que corresponde a 30\%. Ao se tratar de método quantitativo não foi possível identificar nenhuma pesquisa utilizando esse método. Foi constatado que 07 artigos, que corresponde em $70 \%$, apresentaram os métodos qualitativos com quantitativos, conforme pode ser visualizado na Tabela 1.

Tabela 1

Os métodos de pesquisa e a quantidade de suas aplicações

\begin{tabular}{ccc}
\hline Método da Pesquisa & Quantidade & Representação em \% \\
\hline Quantitativo & 0 & 0 \\
Qualitativo & 03 & 30 \\
Qualitativo e Quantitativo & 07 & 70 \\
\hline Total & $\mathbf{1 0}$ & $\mathbf{1 0 0}$ \\
\hline
\end{tabular}

Os resultados acima reforçam os ditos de Scussel (2017), que ressalta sobre a importância do fortalecimento dos estudos multimétodos, em que a lógica positivista e interpretativa quando unidas direcionam o marketing ao estudo dos fenômenos de forma mais completa, atingindo sua totalidade.

Com relação a classificação das pesquisas com base nos objetivos, a Tabela 2 permite-nos visualizar que a pesquisa descritiva com exploratória teve uma representação de $30 \%$ em relação ao total dos artigos estudados. A pesquisa exploratória com explicativa foi de $10 \%$. A pesquisa exploratória representou $20 \%$. Descritiva foi $30 \%$, e os três tipos de pesquisas (explicativo, exploratório e descritivo) juntas foram 10\%.

Tabela 2

Quantidade de pesquisas classificadas com base nos objetivos

\begin{tabular}{lcc}
\hline Base em Objetivo da Pesquisa & Quantidade & Representação em \% \\
\hline Descritivo e Exploratório & 03 & 30 \\
Exploratório e Explicativo & 01 & 10 \\
Exploratório & 02 & 20 \\
Descritivo & 03 & 30 \\
Explicativo, Exploratório e Descritivo & 01 & 10 \\
\hline Total & $\mathbf{1 0}$ & $\mathbf{1 0 0}$ \\
\hline
\end{tabular}

Ao levar em consideração os 10 artigos, foi observado que o método de pesquisa Survey com Experimental está presente em $20 \%$ do total das pesquisas, e somente a Survey aparece com $40 \%$. Já a netnografia com observação representa 10\%. Outros estudos eram bibliográficos sendo inseridos na categoria "não consta" conforme tabela 3 .

Tabela 3

As metodologias utilizadas na pesquisa e a quantidade

\begin{tabular}{lcc}
\hline Metodologia de pesquisa & Quantidade & Representação em \% \\
\hline Experimental e Survey & 02 & 20 \\
Survey & 04 & 40 \\
Netnografia e Observação & 01 & 10 \\
Não consta & 03 & 30 \\
\hline Total & $\mathbf{1 0}$ & $\mathbf{1 0 0}$ \\
\hline
\end{tabular}

O survey apresentou predominância e crescimento dentre os métodos de pesquisa na década de 2000, assim o resultado mostrado na Tabela 3 foi condizente com os resultados da pesquisa de Oliveira et al. (2016). 
Em relação a coleta de dados pode-se constatar que o modo mais utilizado foi o questionário, que representou $50 \%$. Em seguida a entrevista com $20 \%$, e o tipo de coleta observação foi $10 \%$. Algumas pesquisas não foram inseridas na contagem por se classificarem como bibliográficas sendo, portanto, inseridas na classificação da Tabela 4 na categoria "não ocorreu".

\section{Tabela 4}

Tipos de coleta de dados e a quantidade aplicada

\begin{tabular}{lcc}
\hline Tipos de Coleta de dados & Quantidade & Representação em \% \\
\hline Entrevista & 02 & 20 \\
Questionário & 05 & 50 \\
Observação & 01 & 10 \\
Não ocorreu & 02 & 20 \\
\hline Total & $\mathbf{1 0}$ & $\mathbf{1 0 0}$ \\
\hline
\end{tabular}

O volume de aplicação de questionários e a entrevistas mencionados no trabalho de Oliveira et al. (2015) convergem com os resultados apresentados na Tabela 4. Trata-se de um modo de coleta realmente muito aplicado se comparado aos outros métodos existentes.

Ao analisar a autoria dos trabalhos, Petroianu (2002) trata a colaboração intelectual com seriedade, em que a autoria científica deve ser direcionada para os participantes que realmente contribuíram de forma efetiva para que a pesquisa pudesse ter sido realizada. Essa consideração torna-se relevante ao mencionar a ordem dos autores nos trabalhos.

Nassif (2019) argumenta que a ordem dos nomes apresenta fragilidades, porém há de ser aplicado para mensurar a contribuição que cada autor teve no trabalho científico. Assim, para mencionar de qual país pertence o autor do trabalho, foi levado em conta que o principal autor do trabalho para este estudo teria seu nome constando como o primeiro na linha dos nomes dos autores do artigo.

Portanto, o destaque é nítido pois dos trabalhos analisados neste estudo percebe-se que 20\% são de autores do Brasil, e outros 20\% são de autores do Reino Unido. Países como Arábia Saudita, Estados Unidos, França, Holanda, Reino Unido, Rússia e Tailândia tiveram uma representatividade de $10 \%$ cada, assim esses países permaneceram no mesmo patamar.

\section{Tabela 5}

País do principal autor do artigo pesquisado

\begin{tabular}{lcc}
\hline País do principal autor & Quantidade de autores & Representação em \% \\
\hline Arábia Saudita & 01 & 10 \\
Brasil & 02 & 20 \\
Estados Unidos & 01 & 10 \\
França & 01 & 10 \\
Holanda & 01 & 10 \\
Reino Unido & 02 & 20 \\
Russia & 01 & 10 \\
Tailândia & 01 & 10 \\
\hline Total & $\mathbf{1 0}$ & $\mathbf{1 0 0}$
\end{tabular}

Com base nos resultados da Tabela 5, os principais autores dos trabalhos analisados estão localizados em países pertencente à Europa, com uma representação de 50\%, em segundo lugar está o Brasil com 20\%. 
Com base nesse comparativo torna-se interessante perceber a semelhança com os achados de Maranhão e Paula (2012), que enfatizam sobre os principais autores da área de estudos críticos em marketing, afirmando que há presença de autores nacionais, mas o predomínio é de autores europeus.

Torna-se interessante divulgar também a porcentagem dos países alvo de pesquisa. Nem sempre o pesquisador coleta dados do país em que vive. As representações das pesquisas e os países constam na Tabela 6.

\section{Tabela 6}

Países que foram realizadas as pesquisas, ou que foram alvo das pesquisas

\begin{tabular}{lcc}
\hline País escolhido para realizar a pesquisa & Quantidade & Representação em \% \\
\hline Arábia Saudita & 01 & 10 \\
Brasil & 01 & 10 \\
Brasil e América do Norte & 01 & 10 \\
Estados Unidos & 01 & 10 \\
Holanda & 01 & 10 \\
Reino Unido & 02 & 20 \\
Rússia & 01 & 10 \\
Vários países Europa e América do Norte & 01 & 10 \\
Vários países Rússia, USA e Singapura & 01 & 10 \\
\hline Total & 10 & 100 \\
\hline
\end{tabular}

Em relação ao país em que foi realizado ou coletado os dados da pesquisa, o Reino Unido foi alvo de 20\% das pesquisas, enquanto outros países como Arábia Saudita e Holanda apresentaram 10\%. Brasil, Rússia, e outros países tiveram uma participação um pouco maior do que $10 \%$, pois algumas pesquisas coletaram dados de vários países ao mesmo tempo, incluindo vários países da Europa e da América do Norte.

\subsection{Iramuteq e a frequência das palavras principais no resumo}

Depois de lido os 10 resumos e identificados como apropriados ao tema, onde também leu o artigo na íntegra, achou-se interessante levantar a quantidade de aparição das palavras chaves. Para facilitar essa tarefa foi utilizado o software Iramuteq.

Os 10 resumos, relativos aos artigos selecionados apresentaram 2.323 palavras, onde $61,45 \%$ delas apareceram só uma vez enquanto que $21,83 \%$ são palavras que se repetiram.

Nos 10 resumos a palavra "Consumer" aparece 33 vezes, as palavras "On-line" 39, e "Behavior" (comportamento) 11, "Behaviour" 4, "Market" 12, "Concept" 11, "Customer" 11.

Importante ressaltar que na Tabela 7 e nas próximas figuras, o fato da quantidade de palavras estar representada por um sinal negativo, não significa que a palavra é inexistente no resumo. A palavra consta no resumo sim, só que em pouca quantidade se comparada como o número máximo de repetições da mesma.

Em se tratando de frequência das palavras no texto, os resumos apresentaram os seguintes resultados conforme apresentados na Tabela 7.

Tabela 7

Frequência das palavras no resumo dos artigos analisados

\begin{tabular}{lrrrrrrrrrr}
\hline Palavra & Art.1 & Art.10 & Art.2 & Art.3 & Art.4 & Art.5 & Art.6 & Art.7 & Art.8 & Art.9 \\
\hline Behavior & 0 & 3 & 2 & 2 & 0 & 0 & 0 & 2 & 2 & 0
\end{tabular}




\begin{tabular}{lllllllllll} 
Behaviour & 0 & 0 & 0 & 0 & 0 & 2 & 0 & 0 & 0 & 0 \\
Concept & 1 & 1 & 1 & 1 & 2 & 1 & 1 & 1 & 0 & 2 \\
Consumer & 7 & 2 & 3 & 3 & 1 & 1 & 2 & 4 & 8 & 2 \\
Customer & 0 & 0 & 0 & 0 & 8 & 0 & 0 & 0 & 1 & 2 \\
Market & 1 & 0 & 1 & 4 & 2 & 1 & 0 & 0 & 0 & 3 \\
\hline On-line & 2 & 3 & 2 & 6 & 3 & 5 & 7 & 1 & 5 & 5 \\
\hline
\end{tabular}

No quadro acima os números demonstram as palavras em comum nos artigos. Fica explícito que os artigos 10, 02, 03, 05, 07 e 08 possuem no resumo de forma simultânea as 3 palavras principais para esse estudo que são "Behavior" ou "Behaviour", "Consumer" ou "Customer" e "On-line". Desse modo, esse quadro serve para facilitar a visualização para comparar a aparição das palavras nos artigos.

Em se tratando de frequência a palavra "Consumer" tem aparição nos resumos dos artigos 01, 10, 02, 03, 04, 05,06, 07, 08 e 09. Vale ressaltar que no resumo do artigo 04 a palavra "Consumer" consta uma aparição, porém a palavra "Customer" aparece 08 vezes, o que leva a acreditar que o autor preferiu utilizar o segundo termo ao invés do primeiro para identificar o comprador, conforme apresenta os dados na Figura 2.

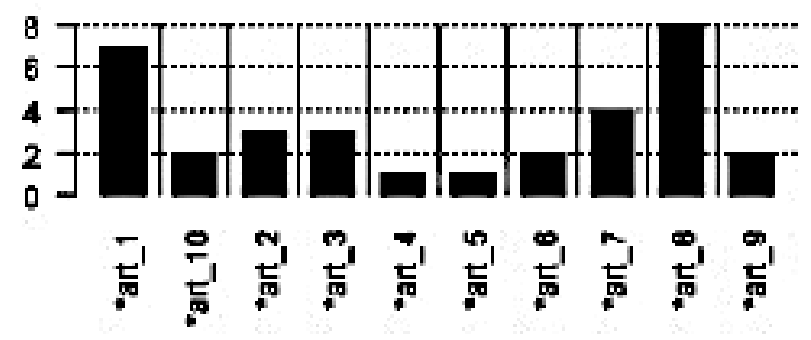

consumer

Fig. 2. Frequência de aparição da palavra "Consumer" no resumo

A palavra "Concept" na Figura 3 tem aparição nos textos 01, 10, 02, 03, 04, 05, 06, 07 e 09, mas isso não representa que os artigos abordaram os conceitos sobre comportamento do consumidor on-line. E o texto 04 e 09 apresentam elevado volume de aparição. Já no texto 08 a palavra não é mencionada.

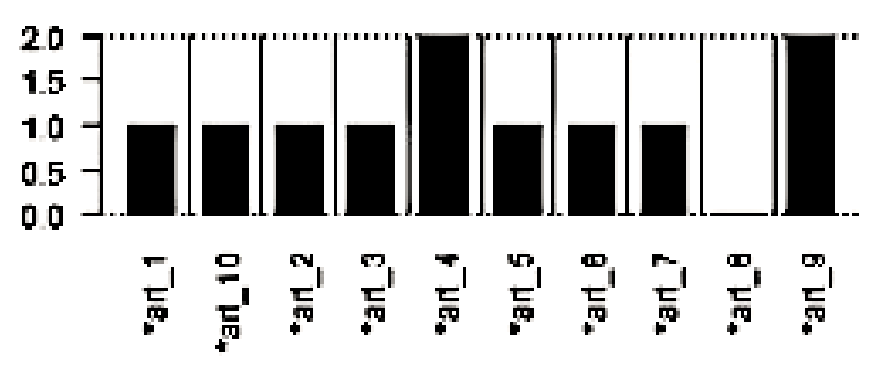

Fig. 3. Frequência de aparição da palavra "Concept" no resumo

Na Figura 4, a palavra "Behavior" aparece nos textos 10, 02, 03, 07 e 08, com mais evidência nos textos 10, cuja palavra foi mencionada maior número de vezes se comparada com os outros textos. Notase que apenas 50\% dos artigos abordam o termo "comportamento", ou seja, já demonstra a deficiência na produção quando envolve essa palavra. A escassez estãonos textos 01, 04, 05, 06 e 09. 


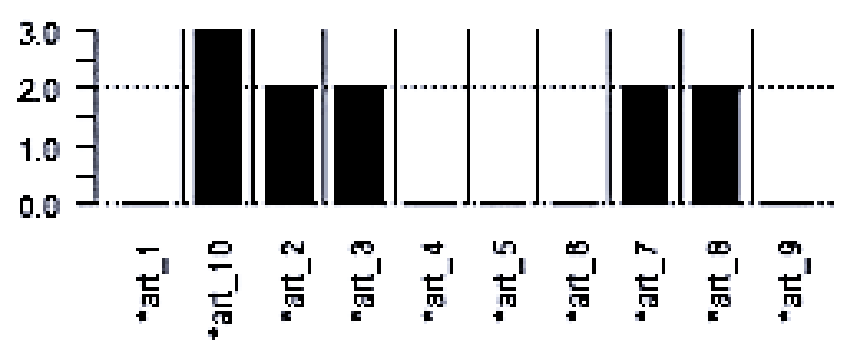

Fig. 4. Frequência de aparição da palavra "Behavior" no resumo

A palavra "On-line" tem alta representatividade em todos os resumos dos artigos, com um volume maior no texto 06 . O resumo que apresenta menos menção da palavra "on-line" é a do artigo 07, conforme consta na Figura 5.

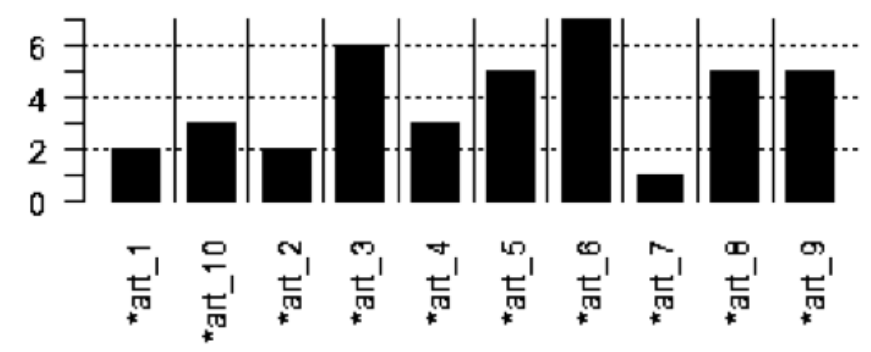

Fig. 5. Frequência de aparição da palavra "On-line" no resumo

Em se tratando da frequência a palavra "Market" na Figura 6 tem aparição nos resumos dos artigos 01, 02, 03, 04, 05 e 09. Já nos resumos 10, 06, 07 e 08 não consta a palavra, conforme Figura 6.

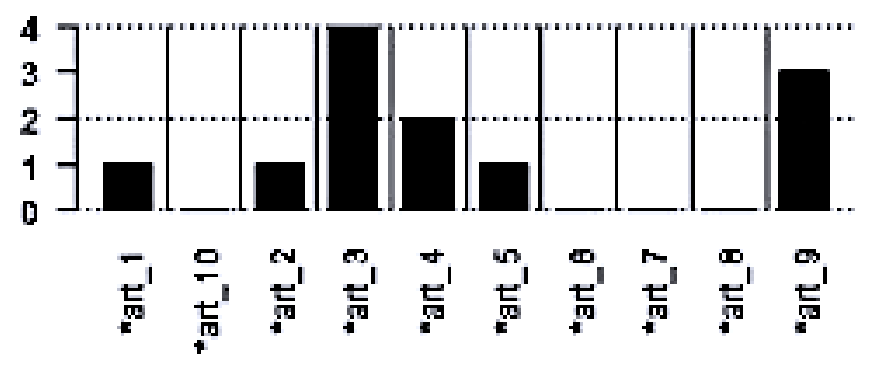

Fig. 6. Frequência de aparição da palavra "Market" no resumo

Abaixo é possível visualizar que a palavra "Customer" foi mencionada no resumo do artigo 04 mais vezes do que o artigo 08 e 09 . Os outros artigos não utilizaram a palavra "Customer" para identificar o comprador, mas sim, o termo "Consumer". Assim os outros artigos os índices estão na casa do zero, conforme Figura 7.

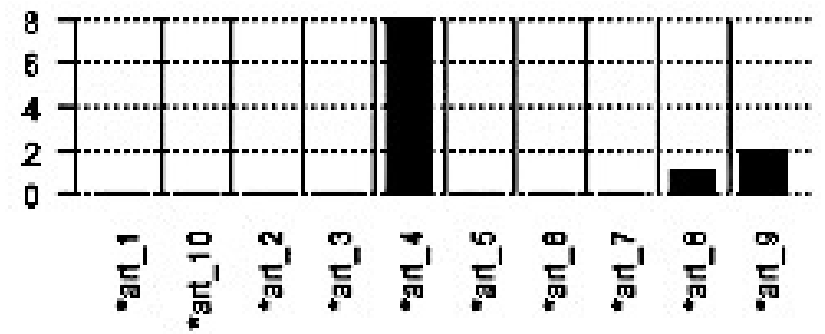

Fig. 7. Quantidade citada da palavra "Customer" 
com o tema, viu-se que a palavra "Customer" estava substituindo a palavra "Consumer". Isso justifica esse volume baixo apresentado na Figura 7.

\subsubsection{Nuvem de palavras}

A nuvem de palavras permitiu uma análise de conteúdo dos termos utilizados no resumo dos artigos, apresenta como termo central de maior tamanho e destaque a palavra "On-line", que dos resumos dos 10 artigos analisados, foi a mais mencionada.

O programa informático Iramuteq, tanto como o programa Wordle executam a organização das palavras por meio da "nuvem de palavras" em que Prais e Rosa (2017) mencionam que este programa oportuniza organizar as palavras em diversas cores e tamanhos com referência no volume de menções no texto.

Igualmente pode-se constatar na nuvem de palavras que os termos seguintes destacados foram "Consumer" e depois as duas palavras "Study" e "Social". As duas últimas palavras tiveram destaque e apresentaram o mesmo tamanho, que pode ser pelo fato de estarem associados aos estudos para obter avanço no conhecimento e a proximidade na questão de conhecer e entender melhor o perfil das pessoas envolvidas. Isso pode estar nas relações de compras de produtos e que entender cada vez mais o comportamento das mesmas é a chave para melhorar os negócios.

As próximas palavras que tem destaque, permitem explanar que os assuntos produto e marca estão unidos para melhorar os negócios com o consumidor on-line. As palavras são: product, brand e engagement.

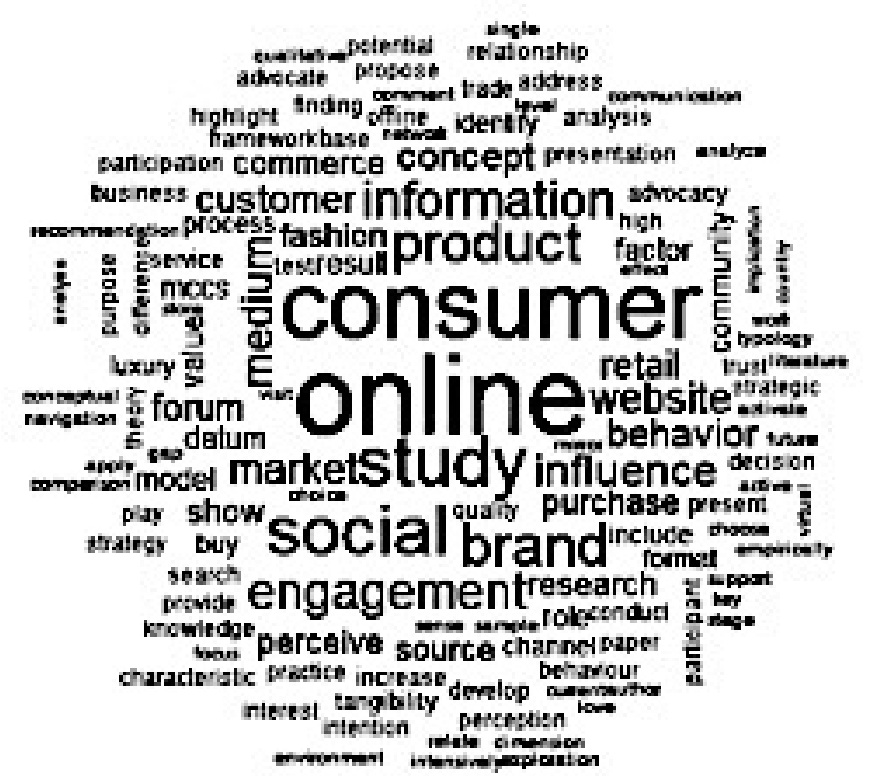

Fig. 08. Representação gráfica dos termos mais comuns no resumo dos artigos

A nuvem de palavras conforme apresentada na Figura 08 demonstra organização das palavras mais importantes e que são mais evidenciadas. Tafazoli (2013) cita que essas ferramentas facilitam o entendimento, pois oferecem dados em formatos variados para melhor compreensão por meio de animação visual e textual.

\subsubsection{Mapeamento das palavras}

As palavras podem apresentar ligações quando discutidas ao redor de um tema. A nuvem de palavras por meio do software utilizado neste estudo disponibilizou a indicação de palavras e a relação entre elas, e isso permitiu unir esta atividade inicial à retomada para elaboração de um mapa conceitual (Prais\& Rosa, 2017). 


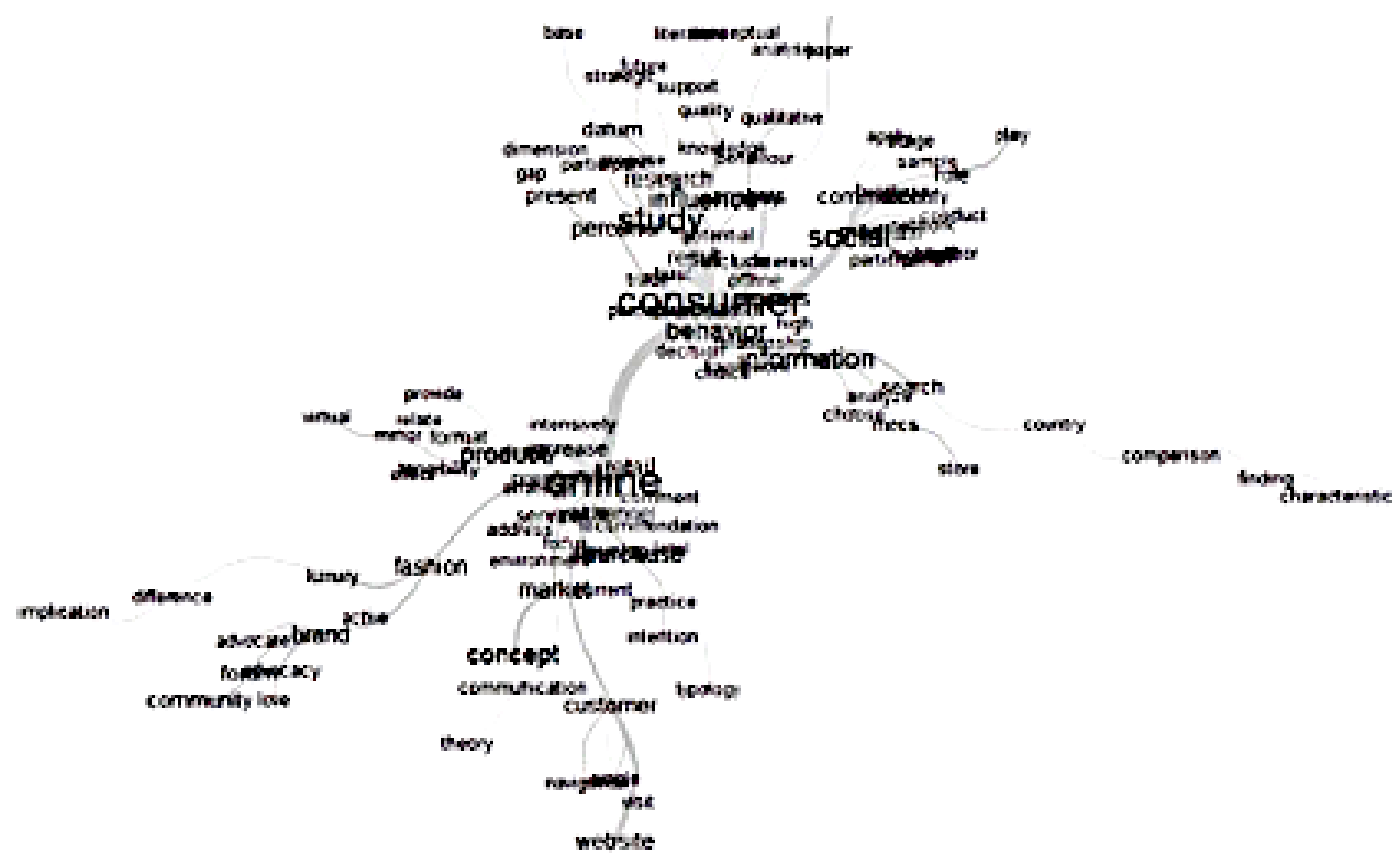

Fig. 09. Representação gráfica da relação entre os termos dos resumos dos artigos

Os artigos tem citado em maior número a palavra "Consumer" e "On-line", basta conferir o tamanho da palavra, que são as maiores se comparadas com as outras, e o distanciamento entre as mesmas.

Percebe-se que o termo "Consumer" está rodeada por palavras que se ligam com o âmbito humano e social, por exemplo: social, study (estudos), behavior( comportamento), influence (influencia). Enquanto que “On-line" está cercada por product (produto), purchase (compra), market(mercado), customer(comprador).

Esse mapa permite visualizar que os estudos que apresentam essas duas palavras não tem forte conexões, ou seja, os artigos que abordam o tema consumer (consumidor) ainda não possuem tanta aderência com online (on-line). Isso pode revelar que as obras acadêmicas poderiam aprofundar e buscar conhecer melhor sobre o assunto como "Consumidor on-line" ou "Consumidor no meio on-line" Consumidor no comércio on-line" e outros.

\section{Considerações}

Na questão das metodologias aplicadas, este estudo apresentou resultado heterogêneo. O fato se explica devido a diversidade de métodos utilizados, porém uns em maior volume e outros em menor.

É importante ressaltar que os estudos não devem partir para um único método, pois vários estudos de um tema quando se utiliza de métodos distintos trazem muitas respostas que podem se complementar. Deste modo a análise dos métodos foi importante para mensurar quais são os mais utilizados nos trabalhos publicados no período de 2014 a 2018, neste quesito oportuniza o início de outros métodos.

Portanto os resultados deste estudo em relação aos objetivos da pesquisa, revelaram que a classificação exploratória está presente em $70 \%$ das pesquisas, trazendo a percepção de que a aproximação por meio dos estudos para conhecer melhor sobre um tema está predominando quanto aos objetivos de uma pesquisa.

Ao mesmo tempo ocorreu o predomínio de $70 \%$ do método qualitativo com quantitativo, 30\% qualitativo, e não houve pesquisa exclusivamente quantitativa. Este resultado traz a percepção de que segundo Scussel (2017), as pesquisas qualitativas também possibilitam contribuir com a evolução do conhecimento, por meio de suas análises críticas e proporciona entender melhor o lado social, assim fica visível que existe também rigor científico além das técnicas estatísticas. 
Ao se deparar com o alto volume de uma metodologia de pesquisa permite-se questionar se aquele resultado ocorre devido a influência de um novo panorama econômico, modismo, ou se o método é escolhido por acreditar ser o mais adequado para aquele tipo de situação. Vieira (2002) menciona que a pesquisa mais apropriada dependerá da própria equipe julgar e analisar os objetivos já preestabelecidos, importante salientar os sistemas tem suas vantagens e limitações.

O modo de pesquisa Survey teve o alcance de $40 \%$ como o modo de pesquisa mais utilizado, e a coleta de dados mais realizada foi o questionário com $50 \%$ de ocorrência. Nesse contexto torna-se perceptível que survey e questionários apresentam ótima parceria para a obtenção de dados.

$\mathrm{Na}$ questão do corpus texto, o uso do software Iramuteq nesta pesquisa demonstrou variadas possibilidades na forma de visualizar as palavras. O termo "On-line" teve maior tamanho diante das outras palavras, e isso dá a entender em âmbito geral que este termo está muito presente na vida das pessoas.

Quanto ao tipo de aproximação das palavras principais ao relacionar com o tema, e a existência da conectividade do próprio assunto aos interesses do estudo foi possível perceber que existe a falta de estudos que unem os dois termos: consumer e on-line. Assim como as palavras "behavour" e "on-line" não estão próximas compreende a necessidade por construir mais estudos sobre o tema que este trabalho abordou.

O presente estudo trouxe como uma de suas contribuições os resultados relacionados quanto a produção científica em consideração aos métodos aplicados. Isso pode deixar evidências sobre o rumo das pesquisas relacionadas ao tema no período selecionado. Dessa maneira, para qualquer estudo já que se trata de novas descobertas e busca de respostas, permite-se por parte dos pesquisadores escolher em dar continuidade ou iniciar outros métodos para novas pesquisas.

\section{Referências}

Barcelos, R. H., \& Rossi, R. H. (2015). A Contribuição da Produção Científica em Marketing para as Ciências Sociais. RAC-Revista de Administração Contemporânea, 19, 197-220.

Bardin L. (1977). L'Analyse de contenu. France: PressesUniversitaires de France.

Chueke, G. V., \& Amatucci, M. (2015). O que é bibliometria? Uma introdução ao Fórum . InternexT - Revista Eletrônica de Negócios Internacionais da ESPM, 10 (2), 01-05.

Collis, J., \& Hussey, R. (2005). Pesquisa em administração: um guia prático para alunos de graduação e pósgraduação. Porto Alegre: Bookman.

Creswell, J. W. (2007). Projeto de pesquisa: método qualitativo quantitativo e misto. Porto Alegre: Artmed.

Gil, A. C. (2002). Como elaborar projetos de pesquisa, 4 ed., São Paulo: Atlas.

Gil, A. C. (2008). Métodos e técnicas de pesquisa social, 6 ed., São Paulo: Atlas.

Gil, B., \& Aranha, S. (2017). Um estudo do gênero abstract na disciplina de Antropologia: a heterogeneidade $\mathrm{da}(\mathrm{s})$ área(s) A studyof abstracts in anthropology: theheterogeneitywithinthefield(s) D.E.L.T.A., 33.3, 843-871.

Kumar, V. (2016). My reflections on publishing in Journal of Marketing. Journal of Marketing, 80, 01-06. 
Maranhão, C. M. S. A., \& Paula, A. P. P. de. (2012). Estudos críticos sobre marketing: levantamento da produção científica. Revista Adm. FACES Journal, 11 (1), 34-46.

Marconi, M.A., \&Lakatos, E. M. (2003). Fundamentos de metodologia cientifica. São Paulo: Atlas.

Mazzon, J., \& Hernandez, J. da C. (2013). Produção científica brasileira em marketing no período 20002009. Revista de Administração de Empresas, 53(1), 67-80. Retrievedfromhttp://www.redalyc.org/articulo. oa?id=155125720005

Moreira, L. F. (2018, novembro). Lealdade a Marca: Analise da Produção Científica na Área do Marketing no Período entre 2013 a 2018. XVII Mostra de Iniciação Cientifica, Caxias do Sul, R.S, Brasil,18.

Motta, A. M., \& Iizuka, E. S. (2018). Análise da produção do journalof marketing de 2014 a 2016 . REMark - Revista Brasileira de Marketing , 17 (4).

Nassif, V. (2019). Autoria nos Artigos Científicos: Por que a Ordem Importa aos Pesquisadores. Revista de Empreendedorismo e Gestão de Pequenas Empresas, 8 (2), 01-05. doi:http://dx.doi.org/10.14211/regepe. v8i2.1574

Oliveira, M. O. R., Luce, F. B., Sampaio, C. H., Perin, M. G., Santini, F. O., \& Santos, M. J. (2017). Análise da qualidade dos artigos científicos da área de marketing publicados no brasil: as pesquisas survey na década de 2000. REAd, 86 (1), 54-87, | Porto Alegre, R.S. Brasil.

Prais, J. L. S.; \& Rosa, V. F. (2017). Nuvem de palavras e mapa conceitual: estratégias e recursos tecnológicos na prática pedagógica. Nuances: estudos sobre Educação, 28 (1), 201-219.

Petroianu, A. (2002). Autoria de um trabalho cientifico. Revista Associação Médica Brasileira, 48 (1), 60-5.

Prodanovi, C. C., \& Freitas, E. C. de. (2013). Metodologia do trabalho cientifico: Métodos e Técnicas da Pesquisa e do Trabalho Acadêmico. Novo Hamburgo: Feevale.

Ramos, M. G., Lima, M. R., \& Amaral-Rosa, M. P. (2018). Contribuições do software Iramuteq para a análise textual discursiva. Atas Ciaq 1.

Ribeiro, R. R. M., Morassato, C. D. C. del, Raimundini, S. L., \& Moraes, R. O. de (2013). Abordagem metodológica: uma investigação da produção científica em contabilidade gerencial publicada nos anais do congresso USP de controladoria e contabilidade. Revista de Contabilidade Dom Alberto, 2 (3), 68-84.

Schlosser, D. F., Frasson, A. C., \&Cantorani, J. R. H. (2019). Softwares livres para análise de dados qualitativos. Revista Brasileira de Ensino e Tecnologia, 12 (1), 539-550

Scussel, F. B. C. (2017). Poder, paradigmas e domínio na pesquisa em marketing no brasil: uma análise da produção nacional da disciplina a partir das matrizes epistêmicas. Administração: ensino e pesquisa, 18 (3), $518-557$.

Silva, A. H., \&Fossá, M. I. T. (2015). Análise de conteúdo: exemplo de aplicação da técnica para análise de dados qualitativos.Qualit@sRevistaEletrônica, 17 (1).

Tafazoli, D.(2013). Wordling: Using word clouds in teaching English language.International Journal of Instructional Technology and Distance Learning, 10 (8). 
Revista Raunp, v. 12, n. 2, p. 100-115, 2020

Vergara, S. C. (1998). Projetos de relatório de pesquisa em administração. São Paulo: Atlas.

Vieira, V. A. (2002). As tipologias, variações e características da pesquisa de marketing. Revista FAE, 5 (1), 61-70. 